\title{
The aortic translocation (Nikaidoh) procedure: Midterm results superior to the Rastelli procedure
}

\author{
Thomas Yeh Jr, MD, PhD, Claudio Ramaciotti, MD, Steven R. Leonard, MD, Lonnie Roy, PhD, and Hisashi Nikaidoh, MD
}

Objective: Midterm follow-up is analyzed after the aortic translocation (Nikaidoh) procedure, an alternative to the Rastelli procedure for ventriculoarterial discordance, ventricular septal defect, and pulmonary stenosis.

Methods: Nineteen patients underwent a Nikaidoh procedure at a median age of 3.3 years (0.9-9.3 years). The native aortic valve was translocated from the right to the left ventricular outflow tract by full $(n=6)$ or partial $(n=13)$ mobilization of the aortic root. Seven patients with partial mobilization had the right coronary artery reimplanted as a button. The conal septum was divided in 13 patients. The right ventricular outflow tract was reconstructed with either a homograft $(n=4)$ or a right ventricular outflow tract patch $(\mathrm{n}=15)$. The median follow-up was 11.4 years (0.1-23 years), and the median age at follow-up was 17.4 years (1-30 years). Left ventricular outflow tract obstruction and aortic insufficiency were assessed by echocardiography.

Results: One patient died of right coronary arterial ischemia. All remaining patients (95\%) survived. The median survival was 13.6 years (longest, 23.0 years). Seven right ventricular outflow tract reoperations were required in 5 patients $(6$ with obstruction and 1 with pulmonary insufficiency). No reoperations have been performed on the left ventricular outflow tract or aortic valve. No patient had any left ventricular outflow tract obstruction or aortic insufficiency more than mild (mild in 9 patients, trivial in 3 patients, and absent in 6 patients).

Conclusions: Midterm actuarial survival was $95 \%$ after the Nikaidoh procedure. Reintervention for the right ventricular outflow tract is more common when valved conduits are used versus valveless reconstruction; however, the Nikaidoh procedure provides complete freedom from important aortic insufficiency and left ventricular outflow tract obstruction.

From The University of Texas, Southwestern Medical Center at Dallas, Tex.

Received for publication Sept 6, 2006; revisions received Oct 2, 2006; accepted for publication Oct 9, 2006.

Reprint requests: Thomas Yeh Jr, MD, $\mathrm{PhD}$, The University of Texas, Southwestern Medical Center at Dallas, Children's Medical Center Dallas, 1935 Motor Street, Suite E03-320.Z, Dallas, TX 75235 (E-mail: yehjr@aol.com).

J Thorac Cardiovasc Surg 2007;133:461-9

$0022-5223 / \$ 32.00$

Copyright $\odot 2007$ by The American Association for Thoracic Surgery

doi:10.1016/j.jtcvs.2006.10.016
$\mathrm{M}$ anagement of d-transposition of the great arteries (d-TGA), ventricular septal defect (VSD), and pulmonary stenosis (PS) remains a challenge. The arterial switch is contraindicated when PS would be converted to significant aortic stenosis. Late surgical outcomes of the Rastelli procedure ${ }^{1-3}$ have been notable for continuing late mortality. In particular, the development of left ventricular outflow tract (LVOT) obstruction caused by the natural tendency of VSDs to close over time, as well as the inability of the artificial material used to construct the LVOT tunnel to grow, remains a significant cause of morbidity and mortality. ${ }^{4,5}$ Kreutzer and colleagues ${ }^{5}$ suggest that left ventricular dysfunction plays an important role in the disappointing results after the Rastelli operation. The additional limitations of pulmonary homograft reconstruction of the right ventricular outflow tract (RVOT) are well known.

As a result, a search for modifications of and alternatives to the Rastelli procedure has led to a variety of options to manage the LVOT (Table 1). Dearani and colleagues ${ }^{4}$ emphasize the importance of VSD enlargement when perform- 


\author{
Abbreviations and Acronyms \\ $\mathrm{d}$-TGA $=$ d-transposition of the great arteries \\ $\mathrm{ECMO}=$ extracorporeal membrane oxygenation \\ LVOT $=$ left ventricular outflow tract \\ $\mathrm{PS}=$ pulmonary stenosis \\ $\mathrm{REV}=$ réparation á l'étage ventriculaire \\ RVOT $=$ right ventricular outflow tract \\ VSD = ventricular septal defect
}

ing the Rastelli procedure. Rubay and colleagues ${ }^{6}$ proposed the réparation á l'étage ventriculaire (REV) procedure, a modification of the Rastelli procedure that emphasizes the importance of conal resection. We proposed aortic translocation ${ }^{7}$ after a patient undergoing the Rastelli procedure died with biventricular outflow tract obstruction. We were motivated by the complete RVOT mobilization described by Kreutzer and colleagues ${ }^{8}$ for use as a right atrial to pulmonary artery conduit in tricuspid atresia, as well as reports of the Ross procedure for LVOT replacement. ${ }^{9}$

Several options are also available to manage the RVOT (Table 1), as described by their original authors. Notwithstanding these original descriptions, one is free to use each RVOT method independently of the method used to reconstruct the LVOT on the basis of the option with the best outcome. RVOT options include valved graft reconstruction as described by Rastelli and colleagues, ${ }^{2,10}$ or valveless autologous reconstruction as described by Nikaidoh ${ }^{7}$ or Lecompte and colleagues. ${ }^{11}$

The purpose of this report is to present the midterm results of the aortic translocation (Nikaidoh) procedure. We also discuss our results along with published outcomes of the Rastelli and REV procedures.

\section{Materials and Methods}

Institutional review board approval was obtained for retrospective chart review and patient follow-up. Nineteen consecutive patients (12 males) underwent the Nikaidoh procedure between 1983 and 2006 and represent our entire experience (4 procedures were performed by other surgeons at 2 other centers and were attended by Dr Nikaidoh). In that same period, 8 patients with d-TGA, VSD, and PS were managed with procedures other than the Nikaidoh procedure at this institution. Five arterial switches were performed when the pulmonary annulus was large enough to be managed with commissurotomy $(\mathrm{n}=3)$ or resection of membranous subvalvar pulmonary stenoses $(n=2)$. Two Rastelli procedures were performed when major coronaries crossed the RVOT and precluded safe aortic root mobilization. One patient with a single coronary artery and noncommitted VSD underwent a Fontan procedure.

In patients managed with the Nikaidoh procedure, 18 patients had d-TGA, VSD, and PS, and 1 patient had double outlet right ventricle, subpulmonary VSD, and PS. A conal septum was
TABLE 1. Options for managing the left and right ventricular outflow tracts in d-transposition of the great arteries, ventricular septal defect, and pulmonary stenosis

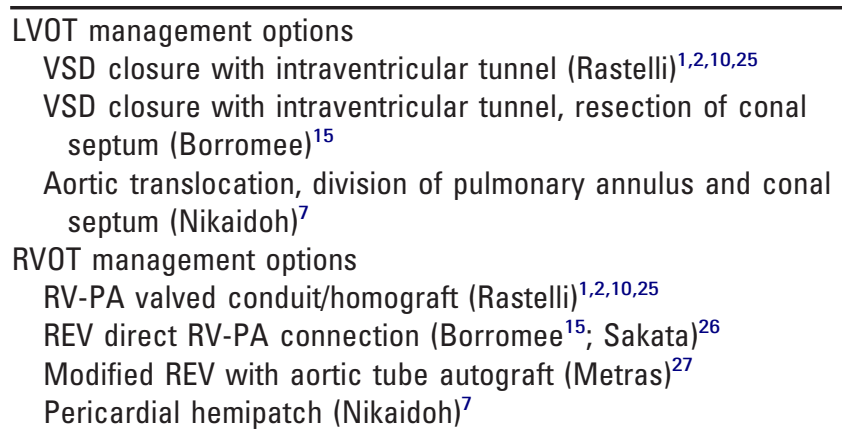

LVOT, Left ventricular outflow tract; $V S D$, ventricular septal defect; RVOT right ventricular outflow tract; $R V-P A$, right ventricular-pulmonary artery; $R E V$, réparation á l'étage ventriculaire.

present in 13 of 19 patients. Preoperative palliation included atrial septostomies and systemic to pulmonary artery shunts. Fourteen balloon atrial septostomies were performed at a median patient age of 2 days. Two patients required no septostomy because their native atrial septal defects were sufficient. The use of septostomy could not be determined in 3 patients. Sixteen of 19 patients had systemic to pulmonary artery shunts (7 classic Blalock-Taussig, 8 modified Blalock-Taussig, and 1 central). Three patients required additional shunts.

The median age at the Nikaidoh procedure was 3.3 years (range 0.9-9.3 years, mean $4.2 \pm 2.4)$. The mean weight and height were $16.1 \pm 6.4 \mathrm{~kg}$ (range $9.8-35 \mathrm{~kg}$ ) and $99 \pm 15.7 \mathrm{~cm}$ (range $75-126$ $\mathrm{cm}$ ), respectively. The mean cardiopulmonary bypass and aortic crossclamp times were $246 \pm 95$ minutes and $105 \pm 56$ minutes, respectively. Two patients required brief circulatory arrest (14 and 8 minutes).

The technical evolution of the Nikaidoh procedure is described in Figure 1. Over time, 2 aortic root mobilization methods were used. Six patients had complete mobilization of their aortic root and both proximal coronary arteries. Thirteen patients had partial mobilization of their aortic root, leaving a pedicle of myocardium under the left main coronary artery, in theory to decrease the risk of bleeding at a point where 3 major suture lines converge (the aortic root anastomosis, VSD patch, and RVOT patch, Figure 1, Panel 6). In all patients, the stenotic pulmonary annulus was divided anteriorly. If a conal septum was present, it too was divided completely (Figure 1, Panel 1B). The LVOT was reconstructed by anastomosing the aortic root to the opened pulmonary annulus posteriorly (Figure 1, Panel $2 A$ ). In 13 patients, the anterior aortic root (Figure 1, Panel $2 B$ ) was anastomosed to the VSD patches of various types ( 6 polytetrafluoroethylene [Gore-Tex, WL Gore and Associates Inc, Newark, Del], 3 Dacron, 4 bovine pericardium). In 6 patients, the VSD was closed using the original right ventricular free wall under the aortic root without a patch. The RVOT was reconstructed with a pulmonary homograft by anchoring the medial wall of the distal main pulmonary artery to the ascending aorta in 4 patients (Figure 1, Panel 6) and overlaying a patch of pericardium to reconstruct the RVOT in 15 patients (Figure 1, Panel 7). 
Follow-up continued for a median of 13.6 years (range 0.1-23 years). The latest follow-up echocardiograms were available in 17 of 18 survivors. Measurements were made with an off-line digitizing system (TomTec Integrated Cardiac Analysis, Broomfield, Colo). The LVOT, RVOT, and ventricular function were assessed. Left ventricular end-diastolic diameter $\mathrm{z}$ scores were obtained on the basis of commercially available data (VMI Medical Inc, Ottawa, Ontario, Canada). The severity of aortic regurgitation was assessed as previously described. ${ }^{12}$ The severity of other valvular regurgitation was graded according to guidelines published by the American Society of Echocardiography. ${ }^{13}$ A qualitative assessment of the right ventricle in comparison with the left ventricle in multiple views, in addition to measurement of the right ventricle in the shortaxis view, was used to assess the presence of right ventricular dilation. ${ }^{14}$

\section{Statistical Methods}

Means are reported as mean \pm standard deviation. Time-related freedoms from death and LVOT or RVOT reintervention were obtained using the Kaplan-Meier method. Time zero was either the date of birth or the date of the Nikaidoh procedure. The outcomes assessed were death, RVOT reintervention, and LVOT reintervention. Patients who had not reached a defined end point at last follow-up were censored. The survival estimates were plotted over time with $95 \%$ confidence intervals.

\section{Results}

\section{Survival and Reoperation}

One patient died after weaning from extracorporeal membrane oxygenation (ECMO) 7 days postoperatively, probably of unrecognized right coronary artery insufficiency. All other patients are surviving with a mean age of 15.6 years (median 17.4 years, maximum 30 years) and a mean survival after the Nikaidoh procedure of 11.4 years (median 13.6 years, maximum 23 years). Actuarial survival from surgery after the Nikaidoh procedure is shown in Figure 2, $A$.

Three patients required ECMO after surgery. Two survived after weaning from ECMO in 3 days. Three patients required early reoperations: (1) a bleeding aortic suture line required revision on cardiopulmonary bypass; (2) kinking in a right coronary artery required reimplantation along with left pulmonary arterioplasty and ECMO; and (3) a chylothorax required thoracic duct ligation. All patients survived early reoperation.

Six patients required late reoperation. One patient required mitral valve repair for endocarditis 1.6 years after the Nikaidoh procedure and is now 20.5 years old. The remaining 5 patients underwent reoperation primarily to address the RVOT. Two patients required 2 homograft replacements: 1 patient underwent reoperation 1.5 and 11.4 years after the Nikaidoh procedure and is now 17.4 years old, and 1 patient underwent reoperation 6.4 and 11.3 years after the Nikaidoh procedure (along with right atrial reduction, cryoablation, and pacemaker placement for atrial flutter) and is now 16.3 years old and in sinus rhythm. One patient required 1 homograft replacement 10.5 years after the $\mathrm{Ni}$ kaidoh procedure (along with tricuspid annuloplasty and Maze procedure) and is now 16.5 years old. One patient required 1 homograft replacement 11.8 years after the $\mathrm{Ni}$ kaidoh procedure and is now 22.1 years old. Finally, 1 patient required pulmonary valve placement 2.1 years after the Nikaidoh procedure (with an RVOT patch) and is now 7.7 years old.

\section{Dysrhythmias}

Atrial flutter developed acutely in 2 patients and 7 years postoperatively in 1 patient. Only 1 of these patients had right coronary ischemia requiring coronary transfer. Two patients underwent Maze procedures. All 18 survivors were in sinus rhythm at the time of their last follow-up. One patient had moderate tricuspid regurgitation; the remainder were trivial or mild. No patient with a history of atrial flutter had significant tricuspid regurgitation. Pulmonary insufficiency was present in 15 of 16 patients, although 2 cases of atrial flutter had no regurgitation. Right ventricular dilation was present in 12 of 16 patients; 1 patient with atrial flutter had no dilation. One of these patients required a pacemaker placement for short-lived sick sinus syndrome with junctional bradycardia after the Maze procedure. The incidence of atrial flutter in this cohort seems higher than we would have predicted.

\section{Right Ventricular Outflow Tract Performance}

Immediate RVOT performance varied by repair method. Four homografts functioned well immediately, but as expected, 2 of 4 homografts eventually required 1 or more replacements. In contrast when the RVOT was reconstructed with a patch, $53 \%$ of patients (8/15) required intraoperative revision, but $80 \%$ of these patients $(12 / 15)$ have not required further RVOT reintervention to date. Twenty percent of patients (3/15) have undergone reoperation primarily for pulmonary insufficiency. One patient required homograft insertion for pulmonary insufficiency, a second homograft and the Maze procedure for atrial flutter, and a pacemaker placement for sick sinus syndrome. This patient is now in sinus rhythm and has good ventricular function. A second patient required a homograft and left pulmonary arterioplasty with residual VSD closure and a second homograft with a takedown of the Glenn shunt. A third patient underwent pulmonary valve insertion and pulmonary arterioplasty for mixed PS and insufficiency.

Actuarial freedom from RVOT intervention (Figure 2, B) shows that of 18 survivors, 5 have required RVOT reintervention, for a $64 \%$ freedom of reintervention at 15 years. Echocardiography in 17 patients showed that right ventricular dilation, RVOT obstruction or regurgitation, and tricuspid regurgitation were identical to findings commonly seen in patients undergoing RVOT surgery. Seventy-three percent of patients had RVOT regurgitation (moderate or severe in $60 \%$, mild in $13 \%$, and none in $27 \%$ ). The systolic 

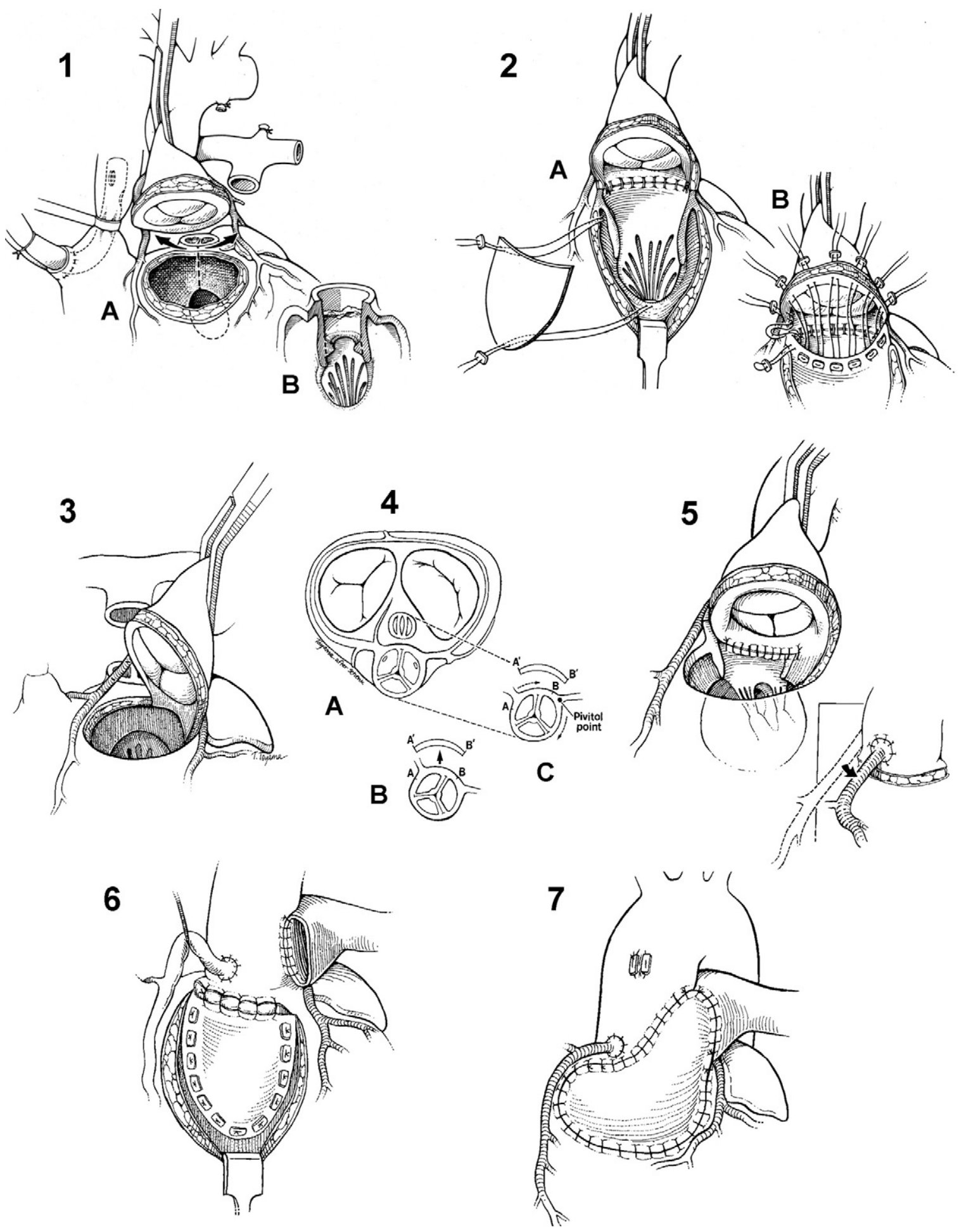

Figure 1. Surgical methods used in aortic translocation cohort.* Panel 1A, We used 2 methods to mobilize the aortic root. In the first, the anteriorly located aortic root is fully mobilized (our currently preferred method) underneath the valve, and both coronaries are skeletonized. Six patients had full mobilization. ${ }^{7}$ Panel 1B, All patients underwent division of pulmonary annulus and conal septum (when present). Pulmonary-mitral continuity is demonstrated. ${ }^{7}$ Panel 2A, Anastomosis of aorta to open pulmonary annulus after posterior translocation. VSD 
gradient across the RVOT was less than $30 \mathrm{~mm} \mathrm{Hg}$ in $80 \%$ of the patients.

\section{Coronary Arteries}

Coronary artery performance also varied by subgroup. Six patients with full aortic root mobilization required no coronary arterial transfer. In contrast, of the 13 patients with partial aortic root mobilization, 7 required right coronary arterial transfer. Four operations were performed primarily, and the outcome was good. Three operations were performed when right coronary arterial insufficiency became evident after cardiopulmonary bypass. Two of these patients who underwent delayed transfer required ECMO. The left main coronary artery was not transferred in any patient. The 1 patient who died (after a period of ECMO support) had not undergone coronary arterial transfer and probably died of unrecognized right coronary artery insufficiency.

\section{Left Ventricular Outflow Tract Performance}

No patient required reoperation on the LVOT (Figure 2, B). Seventeen of 18 survivors were restudied with echocardiography. The LVOT was unobstructed with generally well-preserved systolic function (mean shortening fraction was $34 \% \pm$ $5.7 \%$ ). No patient had more than mild aortic insufficiency, ranging from none in 6 patients, to trace in 3 patients, and to mild in 8 patients. The material used to close the VSD exerted no effect on LVOT performance. The aortic annulus was dilated in the majority of patients $(63 \%)$, but there were no signs of aortic valve distortion or significant regurgitation.

\section{Discussion}

Survival

In recognition of the differences in indication, era, patient selection, and reporting, we have summarized the results (Table 2) and actuarial survival (Figure 3) for the series of patients who underwent the Rastelli ${ }^{4,5}$ (W. G. Williams, personal communication, 2006), $\mathrm{REV}^{3,11,15-19}$ and $\mathrm{Ni}$ kaidoh $^{20,21}$ procedures.

Rastelli procedure. In the 3 largest series, 20-year survival after the Rastelli procedure ranges between $50 \%$ and $60 \%$, including Kreutzer and colleagues' 5 report from Boston. Dearani and colleagues ${ }^{4}$ series from the Mayo Clinic is included, although actuarial analysis excluded operative deaths. Of 231 Rastelli procedures, 71 patients died and 160 early survivors were analyzed. Had operative deaths been included, the Rastelli survival would have been further diminished. Unpublished Rastelli outcomes were also provided by W. G. Williams from Toronto (personal communication, 2006). The similarities in late mortality from 3 experienced centers argues that the Rastelli procedure may not be the ideal approach for d-TGA, VSD, and PS.

Réparation á l'étage ventriculaire procedure. Midterm results for similar periods of follow-up after the REV pro-

patch will be anastomosed to apical rim of VSD. ${ }^{7}$ Panel 2B, Anastomosis of superior portion of VSD patch to anterior rim of mobilized aortic root. ${ }^{7}$ Panel 3, In the second method of mobilizing the aortic root, partial mobilization of the aortic root was used in the early patients. A pedicle of myocardium was left intact under the left main coronary artery to decrease the risk of bleeding where suture lines converge (see Panel 6). Thirteen patients had partial mobilization of the aortic root. Panel $4 A$, In this cross-section of the heart, because the native pulmonary annulus is usually small, aortic translocation does not really move the aorta that far posteriorly. Panel 4B, Fully mobilized roots can shift directly posteriorly without rotation and, we suspect, with less distortion of the coronary arteries. Panel 4C, Partially mobilized roots require rotation of the aortic root around the pedicle of the left main coronary artery. This rotation preserves left main coronary artery alignment, probably at the expense of right coronary arterial alignment. Panel 5, Because of the disproportionate tension on the right coronary artery with partial mobilization and rotation of the root as shown in Panel 4C, the right coronary artery required reimplantation in a subset of patients with partially mobilized aortic roots (7/13 patients). Panel 6, RVOT is reconstructed by anchoring the right lateral wall of the main pulmonary artery to the aortic root and overlaying a patch of pericardium to cover the aortic root, right ventriculotomy, and main pulmonary artery. The pedicled approach was an attempt to minimize bleeding risk under the left main coronary artery where $\mathbf{3}$ major suture lines converge, ie, the root anastomosis, VSD patch, and RVOT patch. In practice, bleeding was never an issue here, and we have discontinued the pedicled approach for the reasons discussed in the text. The RVOT has also been reconstructed with a homografts in 4 patients. Panel 7, Large pericardial patch is used to reconstruct the RVOT. Care must be taken to avoid obstruction of the RVOT. A flat patch is required to curve longitudinally (along the axis of the aorta) and from anterior to posterior (to reach the distal main pulmonary artery). Several patches required intraoperative revision for obstruction. With careful attention to patch configuration, and placement of the corner of the patch into an incision in the left pulmonary artery (not shown), this difficulty has been avoided in our most recent patients. *Panels 1A, 1B, 2A, and 2B were reprinted from Nikaidoh H. Aortic translocation and biventricular outflow tract reconstruction. A new surgical repair for transposition of the great arteries associated with ventricular septal defect and pulmonary stenosis. J Thorac Cardiovasc Surg. 1984;88:365-72, with permission from The American Association for Thoracic Surgery. 

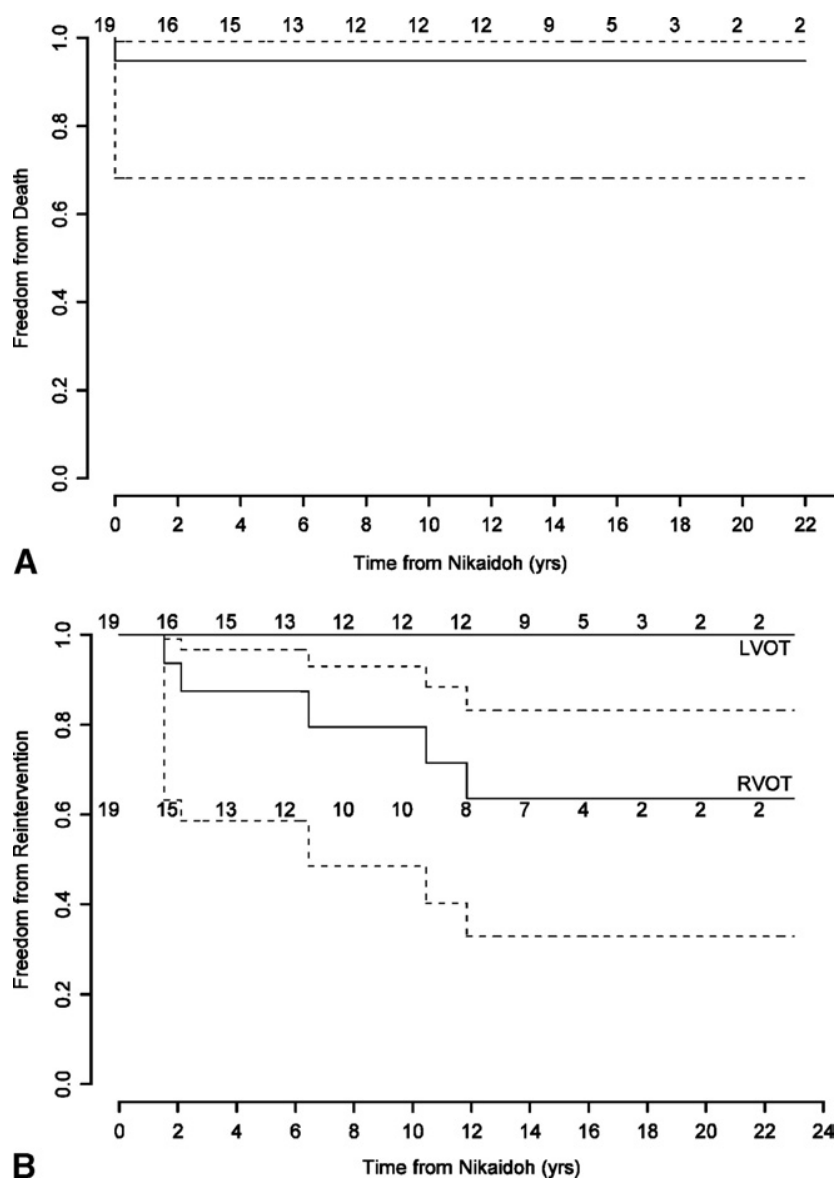

Figure 2. Actuarial analyses after the Nikaidoh procedure. A, Freedom from death. One of 19 patients died in the cohort, for an actuarial freedom from death of $95 \%$. No late deaths have occurred. B, Freedom from LVOT and RVOT reintervention. RVOT reinterventions have been required at rates similar to other procedures using valved conduits or valveless methods to reconstruct the RVOT and are currently $64 \%$ free of reintervention. The Nikaidoh procedure has been $100 \%$ free of reintervention on the LVOT. LVOT, Left ventricular outflow tract; RVOT, right ventricular outflow tract.

cedure have not been formally published; however, in a letter to the editor, Lecompte ${ }^{3}$ reported an operative mortality of $15 \%$ (21/139 patients) and an actuarial survival of $79 \%$ (7 late deaths, 1 noncardiac death) at 15 years. The causes of ongoing mortality were not delineated; however, this longitudinal mortality is concerning. Others have published excellent operative mortalities with the REV procedure as well, but reported follow-up remains brief.

Nikaidoh procedure. No investigator has reported late deaths or LVOT reintervention after the Nikaidoh procedure. ${ }^{7,20}$ In our series we have had 1 operative death and no late deaths. Morell and colleagues ${ }^{20}$ report 1 of 12 operative deaths and no late deaths. Although the Nikaidoh procedure has been criticized for its technical danger, ${ }^{22}$ midterm follow-up indicates that the Nikaidoh procedure is proving to be the safest option over the life of a patient. Although we agree it is a more technically challenging procedure, aortic translocation seems warranted in view of its superior long-term outcomes. We believe that morbidity can be minimized by lessons we have learned.

\section{Right Ventricular Outflow Tract Considerations}

Of patients receiving homograft reconstruction of the RVOT, half are undergoing the expected, repeated operations for RVOT obstruction and homograft replacement.

Patched reconstructions of the RVOT required intraoperative revision in $53 \%$ of the patients. We believe that the difficulty is in forcing a flat pericardial patch to assume a complex configuration that must curve not only around the long axis of the aorta but also from front to back to reach from the anterior ventriculotomy to the posterior main pulmonary artery. In addition, posterior movement of the ascending aorta and the forward movement of the pulmonary confluence can compromise the right pulmonary artery. In longer follow-up, however, the patches have remained relatively free of reintervention. The Lecompte maneuver has been reported by Morell and colleagues ${ }^{20}$ with excellent results. Although we have no experience with this option, care must be exercised to avoid disturbing the aortic sinotubular junction when transecting the aorta.

In midterm follow-up, the design of the Nikaidoh procedure does nothing to improve on outcomes using valved pulmonary conduits (conduit stenosis, insufficiency, and high reoperation rate) or on those using valveless RVOT reconstruction methods. With respect to valveless methods as ours, the REV as described by Rubay and colleagues, ${ }^{6}$ or the tube autograft described by Metras and Kreitmann, ${ }^{16}$ all demonstrate a low incidence of reintervention in the midterm; however, it seems likely that pulmonary valve implantations will ultimately be necessary, much the same as they are in other cases of free pulmonary insufficiency. The issue of whether valved conduits with their early reoperations, or valveless techniques with free pulmonary insufficiency but a lower incidence of early reoperation, will provide better longitudinal outcomes has yet to be answered. We believe that valveless options are outperforming valved conduits in the midterm.

\section{Coronaries}

In aortic translocation, we now transfer coronaries selectively when tension is apparent and preferably before weaning cardiopulmonary bypass. Coronary artery tension is directly related to the diameter of the pulmonary annulus; that diameter is the distance the aortic root must be moved (Figure 1, Panel 4A). ${ }^{7}$ 
TABLE 2. Summary of reported results for the Rastelli, réparation á l'étage ventriculaire, and Nikaidoh procedures

\begin{tabular}{|c|c|c|c|c|c|c|c|c|c|c|}
\hline Procedure & Author & $\begin{array}{c}\text { Starting } \\
\text { year }\end{array}$ & $\begin{array}{c}\text { Finishing } \\
\text { year }\end{array}$ & $\begin{array}{c}\text { Median } \\
\text { age at } \\
\text { surgery (y) }\end{array}$ & $\begin{array}{l}\text { Mean age } \\
\text { at surgery } \\
\text { (y) }\end{array}$ & $\begin{array}{l}\text { Youngest } \\
\text { patient (y) }\end{array}$ & $\begin{array}{c}\text { No. of } \\
\text { patients }\end{array}$ & $\begin{array}{c}\text { No. of } \\
\text { operative } \\
\text { survivors }\end{array}$ & $\begin{array}{l}\text { Operative } \\
\text { survival }\end{array}$ & $\begin{array}{l}\text { Midterm } \\
\text { survival } \\
\text { (raw) }\end{array}$ \\
\hline \multirow[t]{3}{*}{ Nikaidoh } & Yeh & 1983 & 2006 & 3.3 & 4.2 & 0.9 & 19 & 18 & $95 \%$ & $95 \%$ \\
\hline & Morell et al ${ }^{20}$ & 1996 & 2004 & 2.0 & - & 0.4 & 11 & 11 & $92 \%$ & $92 \%$ \\
\hline & del Nido ${ }^{21}$ & - & 1998 & 2.3 & - & 0.25 & 4 & 4 & $100 \%$ & $100 \%$ \\
\hline \multirow[t]{5}{*}{ Rastelli } & Kreutzer et al ${ }^{5}$ & 1973 & 1998 & 3.1 & - & 0.3 & 101 & 94 & $93 \%$ & $76 \%$ \\
\hline & Dearani et al ${ }^{4}$ & 1968 & 2000 & 8.0 & 9.7 & 1.0 & 231 & 160 & $69 \%$ & $46 \%$ \\
\hline & $\begin{array}{l}\text { W. G. Williams, MD } \\
\text { (personal } \\
\text { communication, } \\
\text { 2006) }\end{array}$ & - & - & 5.4 & - & 0.2 & 80 & 70 & $95 \%$ & $71 \%$ \\
\hline & Lee et $\mathrm{al}^{17}$ & 1990 & 2002 & - & 3.3 & - & 10 & 10 & $100 \%$ & $100 \%$ \\
\hline & Vouhe et $\mathrm{al}^{18}$ & 1980 & 1990 & - & 8.1 & - & 22 & 20 & $91 \%$ & $86 \%$ \\
\hline \multirow[t]{7}{*}{ REV } & Lecompte et al ${ }^{11}$ & 1980 & 1981 & - & - & 0.3 & 13 & 9 & $69 \%$ & 一 \\
\hline & Borromee et $\mathrm{al}^{15}$ & 1980 & 1985 & - & 3.5 & 0.3 & 50 & 41 & $82 \%$ & $80 \%$ \\
\hline & Lecompte $^{3}$ & 1980 & - & - & 3.1 & - & 139 & 118 & $85 \%$ & $80 \%$ \\
\hline & $\begin{array}{l}\text { Metras and } \\
\text { Kreitmann }^{16}\end{array}$ & 1993 & - & - & 2.4 & 0.2 & 19 & 19 & $100 \%$ & $100 \%$ \\
\hline & Lee et al ${ }^{17}$ & 1990 & 2002 & - & 2.0 & - & 25 & 24 & $96 \%$ & $96 \%$ \\
\hline & Vouhe et $\mathrm{al}^{18}$ & 1980 & 1990 & - & 3.3 & - & 40 & 35 & $88 \%$ & $85 \%$ \\
\hline & Pretre et $\mathrm{al}^{19}$ & 1986 & 1999 & 1.3 & - & 0.3 & 42 & 39 & $93 \%$ & $93 \%$ \\
\hline
\end{tabular}

KM, Kaplan-Meier, RVOTO, right ventricular outflow tract obstruction; LVOTO, left ventricular outflow tract obstruction; Al, aortic insufficiency; REV, réparation á l'étage ventriculaire. Caution is required in direct comparison of these studies. Among each are differences in centers, eras, diagnoses, surgical procedure, patient selection, and duration of follow-up. Some series have included all results; others have overlapping, noninclusive cohorts. Actuarial analyses of survival and freedom from LVOT or RVOT reintervention are listed where available. For complete information, the reader is referred to the original study. Of particular note, in Kreutzer and colleagues' ${ }^{5}$ study, no operative Rastelli deaths have occurred in the last 7 years, which is suggestive of an era effect. In this patient-based analysis, raw freedom from RVOT intervention may be higher because some of the patients treated with surgery and catheter intervention may have overlapped, but actuarial analysis is provided. * Mean midterm follow-up is actually reported as a median in this series. In Dearani and colleagues' ${ }^{4}$ Rastelli series, operative mortality was excluded from their actuarial survival analysis. Operative mortality by era was as follows: 1968-1977, 24.4\%; 1977-1988, not provided; 1988-1997, 5\%. In Pretre and colleagues' ${ }^{27}$ study, survival was $92 \%$ at 5 years, but actuarial survival was not published. In Vouhe and colleagues ${ }^{26}$ study, operative survival was $89 \%$ for the last 36 patients in the series.

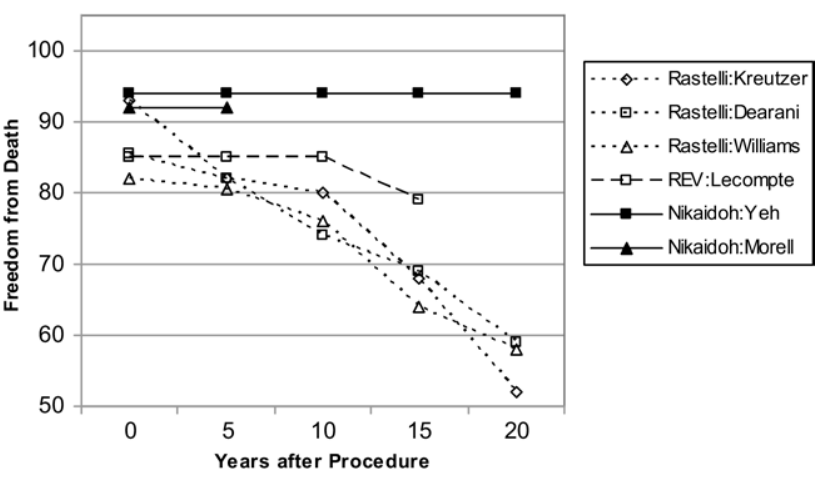

Figure 3. Summary of longitudinal follow-up of Nikaidoh, ${ }^{20}$ Rastelli (W. G. Williams, MD, personal communication, 2006), ${ }^{4,5}$ and REV procedures. ${ }^{3}$ Survival after the Rastelli procedure has been strikingly similar (50\%-60\%) at 3 experienced centers. Reports on the midterm follow-up (>10 years) on the Lecompte procedure have been limited, reported as $\mathbf{7 9} \%$ at $\mathbf{1 5}$ years. The Nikaidoh procedure has been free of late mortality in this and Morell and colleagues' series. $^{28}$ (Note the Y-axis ranges from $\mathbf{5 0 \%}$ to $\mathbf{1 0 0 \%}$ freedom from death.) $R E V$, Réparation á l'étage ventriculaire.
In our original description, the aortic root was completely mobilized (Figure 1, Panels 1 and 4B). Later, to minimize a theoretic risk of bleeding at confluent suture lines, we began partially mobilizing the aortic root and preserving a pedicle of myocardium under the left main coronary artery (Figure 1, Panels 3, 4C, 5, and 6). In this review, we discovered that the only cases that required coronary artery transfer were a subset of patients in whom aortic roots were partially mobilized. Partial mobilization necessitates rotation of the aortic root around the left main coronary artery, preserving its alignment at the expense of right coronary arterial tension (Figure 1, Panel 4C). Fully mobilized roots can shift directly posteriorly without rotation and, we suspect, with less distortion (Figure 1, Panel 4B). No patient with full mobilization required coronary arterial transfer. We believe we may have avoided right coronary artery kinking by continuing to use full aortic root mobilization, which is our currently preferred technique. We continue to transfer any coronary artery that manifests evidence of tension or when right ventricular function seems abnormal after weaning from cardiopulmonary bypass. 
TABLE 2. Continued

\begin{tabular}{|c|c|c|c|c|c|c|c|c|c|}
\hline $\begin{array}{c}\text { Mean } \\
\text { midterm } \\
\text { follow-up (y) }\end{array}$ & $\begin{array}{l}\text { Absence of } \\
\text { LVOTO } \\
\text { (raw) }\end{array}$ & $\begin{array}{c}\text { Absence of } \\
\text { RVOTO } \\
\text { (raw) }\end{array}$ & $\begin{array}{l}\text { Absence of } \\
\text { significant } \\
\text { Al (>mild) }\end{array}$ & $\begin{array}{l}\text { Freedom from } \\
\text { death (KM, } y)\end{array}$ & $\begin{array}{l}\text { Follow-up } \\
\text { (KM, y) }\end{array}$ & $\begin{array}{l}\text { Freedom from } \\
\text { LVOTO (KM, y) }\end{array}$ & $\begin{array}{c}\text { LVOT } \\
\text { follow-up } \\
\text { (KM, y) }\end{array}$ & $\begin{array}{l}\text { Freedom from } \\
\text { RVOTO (KM, y) }\end{array}$ & $\begin{array}{c}\text { RVOT } \\
\text { follow-up } \\
\text { (KM, y) }\end{array}$ \\
\hline 11.4 & $100 \%$ & $72 \%$ & $100 \%$ & $94 \%$ & 20 & $100 \%$ & 15.0 & $64 \%$ & 15.0 \\
\hline 2.8 & $100 \%$ & $75 \%$ & $73 \%$ & - & - & - & - & - & - \\
\hline- & - & - & $75 \%$ & - & - & - & - & - & - \\
\hline $8.5^{*}$ & $88 \%$ & $23 \%$ & - & $52 \%$ & 20 & $84 \%$ & 15.0 & $22 \%$ & 15.0 \\
\hline 11.9 & - & $59 \%$ & - & $59 \%$ & 20 & - & - & $27 \%$ & 20.0 \\
\hline 9.4 & - & - & - & $59 \%$ & 20 & - & - & - & - \\
\hline 5.9 & $60 \%$ & $20 \%$ & - & - & - & - & - & - & - \\
\hline 4.6 & - & $75 \%$ & - & $83 \%$ & 5 & $95 \%$ & - & $70 \%$ & 7.0 \\
\hline- & - & - & - & - & - & - & - & - & - \\
\hline 1.7 & $100 \%$ & $80 \%$ & - & - & - & - & - & - & - \\
\hline $7.6^{*}$ & $98 \%$ & - & - & $79 \%$ & 15 & - & - & - & - \\
\hline 4.0 & $95 \%$ & $95 \%$ & - & - & - & - & - & - & - \\
\hline 5.9 & $96 \%$ & $79 \%$ & - & - & - & - & - & - & - \\
\hline 4.6 & $100 \%$ & $91 \%$ & - & $84 \%$ & 5 & - & - & $90 \%$ & 7.0 \\
\hline 5.4 & $100 \%$ & $72 \%$ & - & - & - & $100 \%$ & 10 & $51 \%$ & 10 \\
\hline
\end{tabular}

Morell and colleagues ${ }^{20}$ routinely transfer both coronaries in aortic translocation. This may eliminate some of the coronary arterial insufficiency we have noted; however, even in midterm follow-up of the arterial switch, abnormalities in coronary arterial flow have been reported. ${ }^{23,24}$ Coronary ostial stenosis remains a concern, and for this and the reasons discussed next, we have not routinely transferred coronaries.

\section{Left Ventricular Outflow Tract Considerations}

After the Rastelli procedure, Kreutzer and colleagues ${ }^{5}$ reported an $84 \%$ freedom from LVOT reintervention at 15 years. In contrast, Dearani and colleagues ${ }^{4}$ note a $99 \%$ freedom from LVOT reintervention in survivors and attributes this to their low threshold for anterosuperior VSD enlargement and conal septal resection, but the actuarial survival in the series is 59\% at 20 years, despite excluding a significant operative mortality. No comment is made on the presence of LVOT obstruction in the patients who died. ${ }^{4}$ The REV procedure seems to have a low incidence of LVOT obstruction (Metras and Kreitmann ${ }^{16}$ report 1 case of LVOT obstruction in 19 cases, and Lecompte ${ }^{3,17}$ reports 2 cases of LVOT obstruction in 111 survivors of the REV operation), but the operative and actuarial mortalities have been higher than those we observed with the Nikaidoh procedure. ${ }^{3}$ In addition to stable actuarial survival in midterm follow-up, the striking finding after aortic translocation has been the freedom from LVOT reintervention, with no patient having more than mild aortic insufficiency in midterm follow- up. Transection of the conal septum completely relieves any LVOT obstruction, which is an integral part of the procedure.

Morell and colleagues ${ }^{20}$ identified 3 cases of moderate aortic insufficiency in 11 patients who underwent operations at 6 months, 10 months, and 2 years. In a personal communication (2006), Morell relayed that the development of insufficiency was delayed in onset. del $\mathrm{Nido}^{21}$ also reported a case of moderate aortic insufficiency in an abstract. Although the aortic valves in our cohort are generally functioning well, we are circumspect about the potential for aortic insufficiency. In considering this issue, there are several technical differences between our approaches. We selectively reimplant only right coronaries, have not had to implant left coronaries, do not divide the ascending aorta, do not perform a Lecompte maneuver, and operate on slightly older patients. Morell harvests a free autograft (transecting the aorta and detaching the coronaries as buttons), reimplants the autograft by rotating 180 degrees, attempts to reimplant into the existing coronary ostia, performs a LeCompte maneuver, and reconstructs the RVOT with a direct right ventricle to pulmonary arterial connection. He has also decreased the lower age limit to 5 months. del Nido's ${ }^{21}$ aortic root autograft technique also includes an extensive alteration of the native aortic root. These maneuvers may be more likely to disturb the aortic sinotubular junction or geometry of the aortic annulus. Finally, the plasticity of the younger aortic valve may make it more 
prone to distortion in younger patients. Although these theories are conjecture, the importance of preserving aortic valve function will be critical because freedom from LVOT reintervention seems to be the major strength of the Nikaidoh procedure.

\section{Conclusions}

Our current recommendations are complete mobilization of the aortic root to minimize the need for coronary arterial transfer, coronary arterial transfer only when there is evidence of tension, and reconstruction of the RVOT with a valveless patch, taking special care as outlined above to avoid patch obstruction.

RVOT performance after the Nikaidoh procedure is similar to other procedures using valved conduits or valveless methods and does not explain the improved survival in the management of d-TGA, VSD, and PS.

LVOT performance has been excellent, and in midterm follow-up, we see no evidence of LVOT obstruction or important aortic insufficiency after the Nikaidoh procedure. We speculate that this may translate into better left ventricle performance and thus better actuarial survival.

Ongoing referrals and excellent midterm follow-up were provided by several cardiologists involved in the ongoing care of these challenging patients. To these physicians, Ted Carlson, MD, David Fixler, MD, Ernest Kiel, MD, Pennock Laird Sr, MD, Edgar Newfeld, MD, John Pliska, MD, Deborah A. Schutte, MD, Thomas Weigel, MD, Damaris Wright, MD, we are deeply grateful. The authors are indebted to Osman Al Radi, MD, for his assistance in statistical analysis.

\section{References}

1. Rastelli GC, Wallace RB, Ongley PA. Complete repair of transposition of the great arteries with pulmonary stenosis. A review and report of a case corrected by using a new surgical technique. Circulation. 1969;39:83-95.

2. Rastelli GC. A new approach to "anatomic" repair of transposition of the great arteries. Mayo Clin Proc. 1969;44:1-12.

3. Lecompte Y. Rastelli repair for transposition of the great arteries: still the best choice? J Thorac Cardiovasc Surg. 2002;123:192-3.

4. Dearani JA, Danielson GK, Puga FJ, Mair DD, Schleck CD. Late results of the Rastelli operation for transposition of the great arteries. Semin Thorac Cardiovasc Surg Pediatr Card Surg Annu. 2001;4:3-15.

5. Kreutzer C, De VJ, Oppido G, Kreutzer J, Gauvreau K, Freed M, et al. Twenty-five-year experience with Rastelli repair for transposition of the great arteries. J Thorac Cardiovasc Surg. 2000;120:211-23.

6. Rubay J, Lecompte Y, Batisse A, Durandy Y, Dibie A, Lemoine G, et al. Anatomic repair of anomalies of ventriculo-arterial connection (REV). Results of a new technique in cases associated with pulmonary outflow tract obstruction. Eur J Cardiothorac Surg. 1988;2:305-11.

7. Nikaidoh H. Aortic translocation and biventricular outflow tract reconstruction. A new surgical repair for transposition of the great arteries associated with ventricular septal defect and pulmonary stenosis. J Thorac Cardiovasc Surg. 1984;88:365-72.

8. Kreutzer G, Galindez E, Bono H, De PC, Laura JP. An operation for the correction of tricuspid atresia. J Thorac Cardiovasc Surg. 1973; 66:613-21.

9. Ross DN. Replacement of aortic and mitral valves with a pulmonary autograft. Lancet. 1967;2:956-8.
10. Rastelli GC, Ongley PA, Davis GD, Kirklin JW. Surgical repair for pulmonary valve atresia with coronary-pulmonary artery fistula: report of case. Mayo Clin Proc. 1965;40:521-7.

11. Lecompte Y, Neveux JY, Leca F, Zannini L, Tu TV, Duboys Y, et al. Reconstruction of the pulmonary outflow tract without prosthetic conduit. J Thorac Cardiovasc Surg. 1982;84:727-33.

12. Tani LY, Minich LL, Day RW, Orsmond GS, Shaddy RE. Doppler evaluation of aortic regurgitation in children. Am J Cardiol. 1997;80: 927-31.

13. Zoghbi WA, Enriquez-Sarano M, Foster E, Grayburn PA, Kraft CD, Levine RA, et al. Recommendations for evaluation of the severity of native valvular regurgitation with two-dimensional and Doppler echocardiography. J Am Soc Echocardiogr. 2003;16:777-802.

14. Roge CL, Silverman NH, Hart PA, Ray RM. Cardiac structure growth pattern determined by echocardiography. Circulation. 1978; 57:285-90.

15. Borromee L, Lecompte Y, Batisse A, Lemoine G, Vouhe P, Sakata R, et al. Anatomic repair of anomalies of ventriculoarterial connection associated with ventricular septal defect. II. Clinical results in 50 patients with pulmonary outflow tract obstruction. Eur J Cardiothorac Surg. 1988;95:96-102.

16. Metras D, Kreitmann B, Riberi A, Yao JG, el-Khoury E, Wernert F, et al. Extending the concept of the autograft for complete repair of transposition of the great arteries with ventricular septal defect and left ventricular outflow tract obstruction: a report of ten cases of a modified procedure. J Thorac Cardiovasc Surg. 1997;114:746-53.

17. Lee JR, Lim HG, Kim YJ, Rho JR, Bae EJ, Noh CI, et al. Repair of transposition of the great arteries, ventricular septal defect and left ventricular outflow tract obstruction. Eur J Cardiothorac Surg. 2004; 25:735-41.

18. Vouhe PR, Tamisier D, Leca F, Ouaknine R, Vernant F, Neveux JY. Transposition of the great arteries, ventricular septal defect, and pulmonary outflow tract obstruction. Rastelli or Lecompte procedure? J Thorac Cardiovasc Surg. 1992;103:428-36.

19. Pretre R, Gendron G, Tamisier D, Vernant F, Sidi D, Vouhe P. Results of the Lecompte procedure in malposition of the great arteries and pulmonary obstruction. Eur J Cardiothorac Surg. 2001;19:283-9.

20. Morell VO, Jacobs JP, Quintessenza JA. Aortic translocation in the management of transposition of the great arteries with ventricular septal defect and pulmonary stenosis: results and follow-up. Ann Thorac Surg. 2005;79:2089-92.

21. del Nido PJ. Aortic root autograft and arterial switch for management of D-TGA with LVOTO. American Association for Thoracic Surgery, Congenital Heart Disease Symposium. 62-63. 4-25-2004.

22. Lecompte Y, Bex JP. Repair of transposition of the great arteries with ventricular septal defect and left ventricular outflow tract obstruction. J Thorac Cardiovasc Surg. 1985;90:151-2.

23. Pedra SR, Pedra CA, Abizaid AA, Braga SL, Staico R, Arrieta R, et al. Intracoronary ultrasound assessment late after the arterial switch operation for transposition of the great arteries. J Am Coll Cardiol. 2005;45:2061-8.

24. Legendre A, Losay J, Touchot-Kone A, Serraf A, Belli E, Piot JD, et al. Coronary events after arterial switch operation for transposition of the great arteries. Circulation. 2003;108(Suppl 1):II186-II190.

25. Rastelli GC, McGoon DC, Wallace RB. Anatomic correction of transposition of the great arteries with ventricular septal defect and subpulmonary stenosis. J Thorac Cardiovasc Surg. 1969;58:545-52.

26. Sakata R, Lecompte Y, Batisse A, Borromee L, Durandy Y. Anatomic repair of anomalies of ventriculoarterial connection associated with ventricular septal defect. I. Criteria of surgical decision. J Thorac Cardiovasc Surg. 1988;95:90-5.

27. Metras D, Kreitmann B. Modified Rastelli using an autograft: a new concept for correction of transposition of the great arteries with ventricular septal defect and left ventricular outflow tract obstruction (with an extension to other congenital heart defects). Semin Thorac Cardiovasc Surg Pediatr Card Surg Аппи. 2000;3:117-24.

28. Morell VO, Jacobs JP, Quintessenza JA. The role of aortic translocation in the management of complex transposition of the great arteries. Semin Thorac Cardiovasc Surg Pediatr Card Surg Annu. 2004;7:80-4. 